\title{
Treatment Results of Vocal Process Granuloma: Intubation Versus Contact Granuloma
}

\author{
Jin Uk Jeong $\mathbb{D}^{\mathbb{D}}$, Jae Hwan Oh $\mathbb{D}^{\mathrm{D}}$, Seul Kim $\mathbb{D}^{\mathrm{D}}$, Dong Young Kim $\mathbb{D}^{\mathbb{D}}$, and Joo Hyun Woo (D) \\ Department of Otohinolaryngology-Head and Neck Surgery, Gachon University College of Medicine, Gil Medical Center, Incheon, Korea
}

삽관성 육아종과 접촉성 육아종에 대한 치료 결과 분석

정진욱, 오재환, 김 슬, 김동영, 우주현

가천대학교 의과대학 길병원 이비인후과학교실

Background and Objectives Vocal process granulomas (VPGs) are benign lesions of the larynx, typically contact granulomas (CG) and intubation granulomas (IG). The two diseases are known to have different clinical manifestations despite having the same pathological features. The purpose of this study was to analyze the treatment results for CG and IG and to obtain clinical information.

Materials and Method We retrospectively reviewed the medical records of patients diagnosed with VPG between January 2015 and December 2018. The patient's age, sex, medical history, lesion size, lesion type, reflux finding score, response to treatment, duration of treatment, and follow-up period were compared.

Results In total, 32 patients were included in the study, of which 18 were CG and 14 were IG. In the CG group, males were dominant $(n=15,83.3 \%)$, whereas in the IG group, females were dominant $(n=11,78.6 \%)(p=0.0009)$. The response to medical treatment using proton pump inhibitor and steroid inhaler was better in the IG group (11/14, 78.6\%) than in the CG group $(7 / 18,38.9 \%)(p=0.036)$. Of the 14 patients who did not respond to medical treatment, 5 received botulium toxin injections, and all 5 had complete remission. The duration of medical treatment was significantly longer in the IG group ( $p=0.0029$ ).

Conclusion IG was more common in female, and CG was more dominant in male. IG had better response to medical treatment using proton pump inhibitor and steroid inhaler than CG.

Keywords Vocal cords; Larynx; Granuloma; Proton pump inhibitors; Botulinum toxins.

\section{서 론}

성대 육아종은 후두에 생기는 양성 병변으로서[1,2], 대표적으로 삽관성 육아종, 접촉 성 육아종이 있다. 두 질환의 병리학적 차이는 없으며 임상적으로 기도 삽관 후 발생하 는 경우를 삽관성 육아종, 과도한 성문 접촉에 의해 발행하는 경우를 접촉성 육아종이라 고 한다. 성대 육아종의 주요 발생 원인은 음성 남용, 기도 삽관, 위식도 역류, 만성 기침 등이 있으며, 관련 요인이 확인되지 않는 경우 원인을 알 수 없는 것으로 간주한다[3-6]. 각각의 관련 요인이 독립적으로 작용하기 보다는 서로 상호작용하고 효과를 복합화하
Received December 2, 2021

Revised December 8, 2021

Accepted December 9, 2021

\section{Corresponding Author}

Joo Hyun Woo, MD, PhD

Department of Otohinolaryngology-

Head and Neck Surgery,

Gachon University College of Medicine,

Gil Medical Center,

21 Namdong-daero 774beon-gil,

Namdong-gu, Incheon 21565, Korea

Tel +82-32-458-2567

Fax +82-32-467-9044

E-mail woojh@gilhospital.com

\section{ORCID iDs}

Jin Uk Jeong (D)

https://orcid.org/0000-0003-4064-5973 Jae Hwan Oh (1)

https://orcid.org/0000-0002-1180-2581

Seul Kim (1D)

https://orcid.org/0000-0002-5538-6372

Dong Young Kim (D)

https://orcid.org/0000-0001-5485-7198

Joo Hyun Woo (iD)

https://orcid.org/0000-0002-8584-563X

\footnotetext{
This is an Open Access article distributed under the terms of the Creative Commons Attribution Non-Commercial License (https://creativecommons.org/ licenses/by-nc/4.0) which permits unrestricted non-commercial use, distribution, and reproduction in any medium, provided the original work is properly cited.
} 
여 성대 육아종을 유발할 수 있다[7,8]. 삽관성 육아종의 경 우 기도 삽관 시 발생할 수 있는 피열 연골 점막의 손상이나 튜브 유지 중 압력 괴사로 인해 발생할 수 있는 물리적인 요 인을 포함하기 때문에 접촉성 육아종과 임상 양상이 다를 수 있다. 그러나 성대 육아종이 흔치 않은 질환이고, 표준화 된 치료법이 없어 치료자의 선호에 따라 다양한 치료법이 시 행되기 때문에 삽관성 육아종과 접촉성 육아종의 임상 양상 과 치료법을 비교한 연구는 많지 않다. 이에 저자들은 삽관 성 육아종과 접촉성 육아종에 대한 치료 결과 차이점을 비 교하고자 한다.

\section{대상 및 방법}

\section{연구 대상}

이 연구는 2015년 1월부터 2018년 12월까지 성대 육아종 으로 진단되어 치료 받은 환자들을 대상으로 후향적 의무기 록 분석을 통한 연구를 시행하였다. 연구과정은 기관 임상연 구윤리센터에서 허가를 받았다(GDIRB2019-352). 후두내시 경을 통해 피열연골의 성대돌기에 육아종이 발생한 경우를 성대돌기 육아종으로 진단하였으며, 그 중 기도삽관 이후 발 생한 경우를 삽관성 육아종으로 그렇지 않은 경우를 접촉성 육아종으로 진단하였다. 환자는 한 명의 이비인후과 전문의에 의해 동일한 치료 프로토콜에 따라 치료 과정이 진행되었으 며, 이러한 환자들 중 치료 종결로 기록된 환자들만을 포함하 였다. 진료기록을 통해 나이, 성별, 과거병력, 육아종의 크기, 형태, 치료방법, 치료기간, 치료반응, 추적관찰기간 등을 조사 하였으며 접촉성 육아종과 삽관성 육아종을 비교하였다. 육 아종은 크기에 따라 소형(small, 장경이 성대의 넓이보다 작 은 경우), 중형(medium, 장경이 성대의 넓이보다 크고 성대 넓이의 두 배 보다 작은 경우), 대형(large, 장경이 성대 넓이의 두 배 보다 큰 경우)으로 분류하였으며(Fig. 1), 양상에 따라 육아종성(granulomatous)과 궤양성(ulcerative)으로 분류하 였다. 역류관찰지수(reflux finding score)는 첫 내원시의 후
두내시경 사진으로 평가하였으며 한 명의 이비인후과 전문의와 한 명의 4년차 전공의에 의해 각각 두 차례 맹검으로 총 4 회 시행한 결과를 평균하였다[9].

\section{연구 방법}

환자의 치료 과정은 한 명의 이비인후과 전문의에 의해 동 일한 치료 패턴으로 시행되었다. 모든 환자는 일차치료로서 양성자펌프억제제와 경구 스테로이드 흡입제를 2 개월간 사용 하였으며, 이러한 복합 약물 치료에 반응하지 않는 경우 이차 치료를 원하는 환자에 한해 성대 내 보툴리눔 독소 주사를 시행하였다. 보툴리눔 독소는 Botox ${ }^{\circledR}$ (Clostridium botulinum toxin type A; Allergen Inc., Campbell, CA, USA)를 비인두경으로 성대를 관찰하면서 갑상설골막을 통하여 갑상 피열근에 주사하였다. 육아종이 한쪽에 있는 경우는 동측에, 양측인 경우에는 큰 쪽에 $4 \mathrm{IU}$ 주사하였다. 보툴리튬 독소치 료를 원치 않는 환자는 추가적으로 약물치료를 시행하였다.

치료 효과의 판정은 후두경 검사를 통해 육아종이 완전히 사라졌을 때, '완치'(complete remission, CR), 50\% 이상의 뚜 렷한 크기 감소를 보였을 때 '명확한 호전'(marked improvement, MI), 50\% 이하의 감소를 보이거나 변화가 없을 때 '지 속'(stationary, ST), 크기가 증가하였을 때를 '진행'(progression, PG)으로 정의하였다. 최종적으로 '완치', '명확한 호전' 은 치료에 반응이 있는 것으로 판단하여 '반응'(responsible) 으로 기록하였으며 '지속'과 '진행'은 치료에 반응 없는 것으로 판단하여 ‘무반응'(irresponsible)으로 기록하였다.

\section{통계 분석}

치료 결과에 영향을 줄 수 있는 요인을 파악하기 위해 접촉 성 육아종 군과 삽입성 육아종 군의 나이, 성별, 육아종 크기, 육아종 양상, 역류관찰지수, 약물치료 기간, 약물치료 결과, 최종치료 결과를 비교하였으며, 카이 제곱 검정 및 MannWhitney 검사를 통해 두 군의 차이를 검증하였으며, $p<0.05$ 를 두 군간의 유의한 차이가 있는 것으로 하였다. 역류관찰지
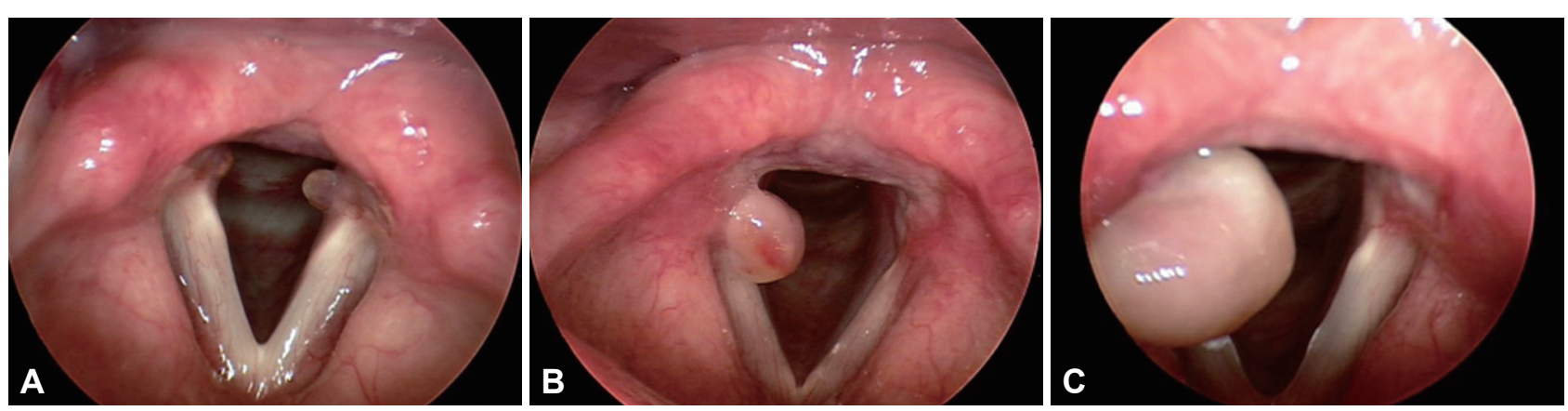

Fig. 1. Classification of granuloma. A: Small size granuloma on left vocal process. B: Medium size granuloma on right vocal process. C: Large size granuloma on right vocal process. 
수는 두 명의 의사에 의해 각각 두 차례 시행된 결과의 평균 값으로 하였으며, 검사자 내부, 검사자간 관찰지수의 일치성과 관련성을 분석하기 위해 Spearman 상관 계수 검사를 시행 하였다.

\section{결 과}

\section{환자 정보 분석 결과}

연구 기간 중 총 61 명의 환자가 성대 육아종으로 진단되었 으며, 접촉성 육아종은 37 명, 삽관성 육아종은 24명이었다. 이들 중 치료 종결 전 추적관찰이 중단된 28명과 결핵성으로 진단된 1 명은 연구에서 제외되었다. 최종적으로 18 명의 접촉 성 육아종 환자와 14 명의 삽관성 육아종 환자가 연구에 포함 되었다(Table 1). 접촉성 육아종 군과 삽관성 육아종 군의 평 균나이는 각각 평균 $53.9 \pm 12.5$ 세, 평균 $44.1 \pm 16.4$ 세로 삽관 성 육아종 환자의 연령이 어렸지만 통계적 유의성은 없었다 $(\mathrm{p}=0.2089) .18$ 명의 접촉성 육아종 군 중 남자는 15 명(83.3\%), 여자는 3명(16.7\%)이었으며 삽관성 육아종 군 중 남자는 3명 (21.4\%), 여자는 11 명 (78.6\%)이었다. 두 질환에 대한 성별 분 포는 유의한 차이를 보였다 $(\mathrm{p}=0.0009)$. 접촉성 육아종은 18 명 모두 일측성이었으며 삽관성 육아종은 14 명 중 4 명은 일 측성, 1 명은 후연합부에 발생하였으며 9 명은 양측성 이었다.

Table 1. Demographic data of the patients with vocal process granulomas

\begin{tabular}{|c|c|c|c|}
\hline Factors & $\begin{array}{l}\text { Contact } \\
(\mathrm{n}=18)\end{array}$ & $\begin{array}{l}\text { Intubation } \\
\quad(\mathrm{n}=14)\end{array}$ & p-value \\
\hline Age (yr) & & & 0.2089 \\
\hline Mean \pm SD & $53.9 \pm 12.5$ & $44.1 \pm 16.4$ & \\
\hline Median (range) & $54(27-72)$ & $43(21-72)$ & \\
\hline Sex & & & $0.0009^{*}$ \\
\hline Male & 15 & 3 & \\
\hline Female & 3 & 11 & \\
\hline Granuloma size & & & 0.5148 \\
\hline Small & 8 & 5 & \\
\hline Medium & 5 & 2 & \\
\hline Large & 5 & 7 & \\
\hline Granuloma type & & & 0.2379 \\
\hline Granulomatous & 13 & 12 & \\
\hline Ulcerative & 3 & 0 & \\
\hline Voice abuse & & & $>0.999$ \\
\hline Yes & 6 & 0 & \\
\hline No & 12 & 0 & \\
\hline Reflux finding score & & & 0.1311 \\
\hline Mean \pm SD & $9.4 \pm 2.2$ & $8.1 \pm 1.6$ & \\
\hline Median (range) & $8.5(5.75-13.25)$ & $7.75(5-10.25)$ & \\
\hline
\end{tabular}

${ }^{*} \mathrm{p}<0.05$ in chi-squared test. SD, standard deviation
크기로 분류하였을 때 접촉성 육아종 군은 소형이 8예, 중 형이 5예, 대형이 5예였으며, 삽관성 육아종 군은 소형이 5예, 중형이 2예, 대형이 7예였다. 두 군에서 육아종의 크기에 대한 유의한 차이는 없었다 $(\mathrm{p}=0.5148)$. 육아종의 양상은 접촉성 육 아종 군에서 육아종성이 13예, 궤양성이 3예였으며, 삽관성 육 아종 군에서는 12예 모두 육아종성이었다. 두 군의 통계적 차 이는 없었다 $(\mathrm{p}=0.2379)$. 역류관찰지수는 접촉성 육아종 군에

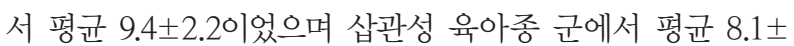
1.6 로 유의한 차이는 없었다 $(\mathrm{p}=0.1311)$. 각각의 검사자가 두 차례 시행한 역류관찰지수의 Spearman 상관 계수는 각각 $\mathrm{r}=$ 0.7629 (95\% confidence interval, 0.5570-0.8825; $\mathrm{p}<0.0001$ ), $\mathrm{r}=0.593$ (95\% confidence interval, $0.2982-0.7845 ; \mathrm{p}=0.0003$ ) 로 두 차례의 독립된 검사가 양의 선형적 상관관계가 있었으 며, 두 평가자 사이의 역류관찰지수의 Spearman 상관 계수 $\mathrm{r}=0.6478$ (95\% confidence interval, 0.3722-0.8165; $\mathrm{p}<$ 0.0001)로 뚜렷한 양의 선형적 상관관계를 보였다.

\section{치료 결과}

양성자펌프억제제와 스테로이드 흡입제를 이용한 약물치료 에서 접촉성 육아종 군 18 명의 환자 중 7명(38.9\%)에서 약물 치료에 반응을 보였다. 이 중 4 명은 완치 되었으며, 3 명은 명 확한 호전을 보였다. 11 명은 무반응으로 나타났으며 그 중 10 명은 지속, 1 명은 진행으로 관찰되었다. 삽관성 육아종 군의 14 명의 환자 중 11 명(78.6\%)에서 치료에 반응을 보였으며 11 명 모두 완치되었다. 3 명은 무반응으로 나타났으며 3명 모두 지속으로 관찰되었다. 약물치료 기간은 접촉성 육아종 군에 서 평균 $3.31 \pm 1.7$ 개월, 삽관성 육아종 군에서 $2.0 \pm 0.8$ 개월 로 접촉성 육아종 군에서 유의하게 길게 나타났다 $(\mathrm{p}=0.0029)$ (Table 2).

약물치료에 반응이 없었던 환자들 중 동의를 얻은 5 명의 환 자에서 성대 내 보톡스 주사가 시행되었다. 접촉성 육아종 군 에서 3 명, 삽관성 육아종 군에서 2 명의 환자에서 시행되었으 며 주사 이후 5명 모두 완치를 보였다(Fig. 2). 최종적으로 치료 반응이 있는 환자는 접촉성 육아종 군에서 10명(10/18, 55.6\%), 삽관성 육아종 군에서 13명(13/14, 92.9\%)을 보였으며 통계적 으로 유의미한 차이를 보였다( $\mathrm{p}=0.0443)$ (Fig. 3).

\section{고 찰}

본 연구는 삽관성 육아종과 접촉성 육아종의 임상 양상과 치료반응 결과를 후향적으로 분석한 연구이다. 임상적으로 삽관성 육아종은 남성보다 여성에서 더 많이 발생하며, 이러 한 이유로는 여성이 상대적으로 작은 후두와 얇은 점막층으로 
Table 2. Treatment results of the patients with vocal process granulomas

\begin{tabular}{lccc}
\multicolumn{1}{c}{ Results } & $\begin{array}{c}\text { Contact } \\
(\mathrm{n}=18)\end{array}$ & $\begin{array}{c}\text { Intubation } \\
(\mathrm{n}=14)\end{array}$ & p-value \\
Medication result & & & $0.0360^{*}$ \\
$\quad$ Responsive (CR/MI) & $7(4 / 3)$ & $11(11 / 0)$ & \\
$\quad$ Unresponsive (ST/PG) & $11(10 / 1)$ & $3(3 / 0)$ & \\
Duration of medication (month) & & $0.0029^{\dagger}$ \\
$\quad$ Mean \pm SD & $3.3 \pm 1.7$ & $2.0 \pm 0.8$ & \\
Median (range) & $3(2-9)$ & $2(1-3)$ & \\
Cases of Botox injection & 3 & 2 & \\
Final result of treatment & & & $0.0443^{*}$ \\
$\quad$ Responsive (CR/MI) & $10(7 / 3)$ & $13(13 / 0)$ & \\
Unresponsive (ST/PG) & $8(7 / 1)$ & $1(1 / 0)$ & \\
Follow-up period (month) & & & $0.0259^{*}$ \\
Mean \pm SD & $4.5 \pm 2.5$ & $2.9 \pm 1.8$ & \\
Median (range) & $4(2-12)$ & $2.5(1-6)$ & \\
\hline
\end{tabular}

${ }^{*} \mathrm{p}<0.05$ in chi-squared test; ${ }^{\dagger} \mathrm{p}<0.05$ in Mann-Whitney U test. CR, complete remission; MI, marked improvement; ST, stationary; PG, progression; SD, standard deviation

인해 삽관성 육아종에 취약하기 때문으로 알려져 있다[10].

기존 연구들에 따르면 성대 육아종의 1차 치료법으로 음성 치료와 양성자펌프억제제를 권장하였으며, 수술적 치료와 보 툴리눔 독소 주사 치료도 보조요법으로 사용된다[3,9,11]. 삽 관성 육아종에 대한 최근 메타 분석에 따르면 치료방법으로 항역류치료, 언어치료, 항염증치료, 스테로이드, 항생제, 황산 아연 및 수술적 치료 등이 모두 시행되고 있으며, 삽관성 육 아종과 접촉성 육아종의 치료 방법은 유사하다고 알려져 왔 다[8]. 그러나 본 연구의 결과에 따르면 삽관성 육아종과 접촉 성 육아종 그룹 간의 복합적인 약물치료에 대한 반응은 유의 한 차이가 있었으며, 삽관성 육아종이 접촉성 육아종보다 양 성자펌프억제제 및 스테로이드 흡입제를 이용한 약물치료에 서 더 우수한 반응을 보이는 것으로 나타났다.

위식도 역류는 성대 육아종에서 중요한 원인 인자로 알려 져 있으며, 위산 역류로 인한 성대의 점막 손상을 억제하기 위 해 성대 육아종의 치료로 양성자펌프억제제 용법이 널리 사 용된다[7,8,12,13]. 스테로이드 흡입제는 성대의 국소염증을 줄 일 수 있으며, 한 연구에 따르면 대부분의 삽관성 육아종이 부데소나이드 흡입제 단독치료만으로 치료될 수 있다고 보고 되어 있다[14]. 따라서, 양성자펌프억제제 및 스테로이드 흡입 제를 이용한 병용 치료는 두가지 다른 기전을 통해 성대 육아 종을 치료할 수 있을 것으로 예상되어 왔다. 이러한 논리에 근 거하여 Hillel 등[7]은 양성자펌프억제제와 스테로이드 흡입제 (트리암시놀론 아세토니드 $300 \mathrm{mcg}$ 1일 3회) 병용 치료로 성 대 육아종 환자군을 치료하였으며, 54 명의 환자에서 62 개의 육아종 중 57 개(69\%)가 치유되었다고 보고했다. 54명의 환자
중 19명(24\%)에서 기도 삽관의 이력이 있었지만 삽관성 육아 종과 접촉성 육아종을 비교하는 별도의 분석은 없었다.

본 연구에서는 양성자펌프억제제 및 스테로이드 흡입제 병 용 치료를 모든 성대 육아종 환자군의 초기 치료로 사용되었 으며, 병합치료의 효과는 삽관성 육아종 $(11 / 14,78.6 \%)$ 군과 접촉성 육아종 $(7 / 18,38.9 \%)$ 군에서 유의한 차이가 확인되었 다. 접촉성 육아종에 비하여 삽관성 육아종의 경우 물리적 자 극을 직접적으로 유발하였던 기도 내 삽관이 일시적이고, 원 인 인자가 치료 중 제거되었기 때문에 삽관성 육아종에서 더 욱 좋은 반응을 보인 것으로 생각된다. 반면 접촉성 육아종의 경우 기도 삽관과 같은 직접적인 요인이 없음에도 불구하고 발생하였으며, 음성 남용 등의 주요 요인이 통제되지 않고 치 료에도 지속되었을 가능성이 있다.

본 연구의 단점으로는 후향적인 연구로 약물치료 기간 및 추적관찰 기간이 너무 짧았다는 것이다. 다만 치료 기간이 길 다고 해서 치료 결과를 신뢰할 수 있는 것을 의미하지는 않는 다. 앞서 언급한 Hillel 등[7]의 연구에서는 평균 11 개월의 치료 기간(1개월 미만-48개월 이상)의 추적관찰을 진행하였는데, 초기에는 약물치료에 반응하지 않던 성대 육아종이 1년 이상 의 치료 이후 감소한 것은 약물치료 이외의 요인에 의한 것일 수 있으며, 약물치료에 대한 반응 정도를 알기에는 어려움이 있다. Wang 등[15]의 연구에 따르면, 성대 육아종 환자 53명 이 특별한 치료 없이 추적관찰을 진행하였을 때 평균 7.5 개월 만에 44명(81\%)에서 완치되었다. 53명의 환자 중 삽관성 육아 종은 15 명이 포함되어 있었으며, 삽관성 육아종 환자군의 완 치 기간은 평균 6 개월로 접촉성 육아종(평균 8.5 개월)보다 유 의하게 짧았다. 즉, 장기간의 치료 기간 진행 시 약물치료에 의 한 효과인지, 자연적인 치유에 의한 것인지 구별하기 어려울 수 있다.

본 연구에서 삽관성 육아종의 경우 접촉성 육아종 환자군 보다 더 우수한 치료 반응과 짧은 치료 기간을 보였다. 이 데 이터를 이전 연구의 결과들과 통합해보면, 삽관성 육아종의 경우 접촉성 육아종보다 약물에 대한 반응이 우수하므로 치 료율이 더 높고 치료 기간이 더 짧다는 것을 의미하며, 삽관 성 육아종의 경우 치료를 하지 않더라도 자연 치유율이 접촉 성 육아종보다 높다는 것을 알 수 있다.

Nasri 등[16]은 1995년 접촉성 육아종의 치료에 보툴리눔 주사를 도입시켰으며, Damrose와 Damrose[17]는 경피적 보 툴리눔 독소 치료가 불응성 성대 육아종의 치료에 안전하고 효과적이라고 보고하였다. 보툴리눔 독소 치료의 원리는 보 툴리눔 독소를 주입하여 일시적 성대 마비를 유발시킴으로써 성문의 조임을 줄이고 육아종과 반대측 피열 연골과의 접촉 을 피하게 하는 것이다. 본 연구에서 약물에 반응하지 않은 

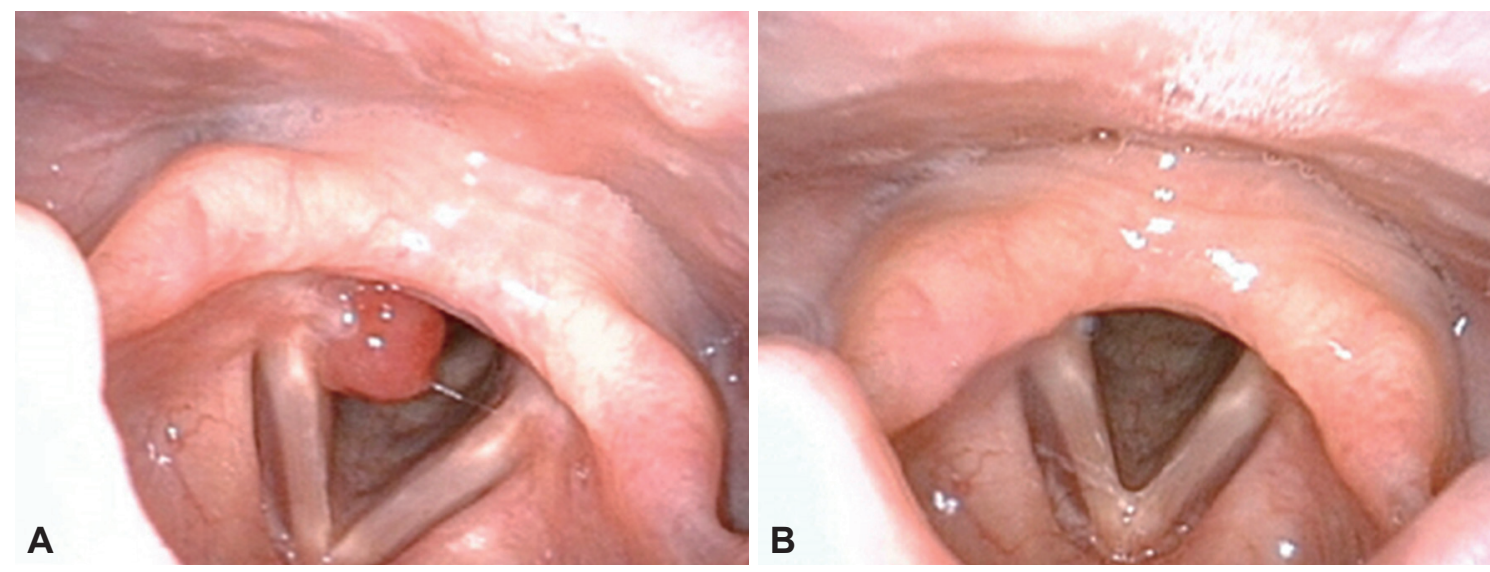

Fig. 2. A twenty one-year-old female patient who complained voice change after plastic surgery underwent botulinum toxin injection on right vocal fold via trans-cricothyroid membrane. A: Before botulinum toxin injection. B: Three months after botulinum toxin injection.

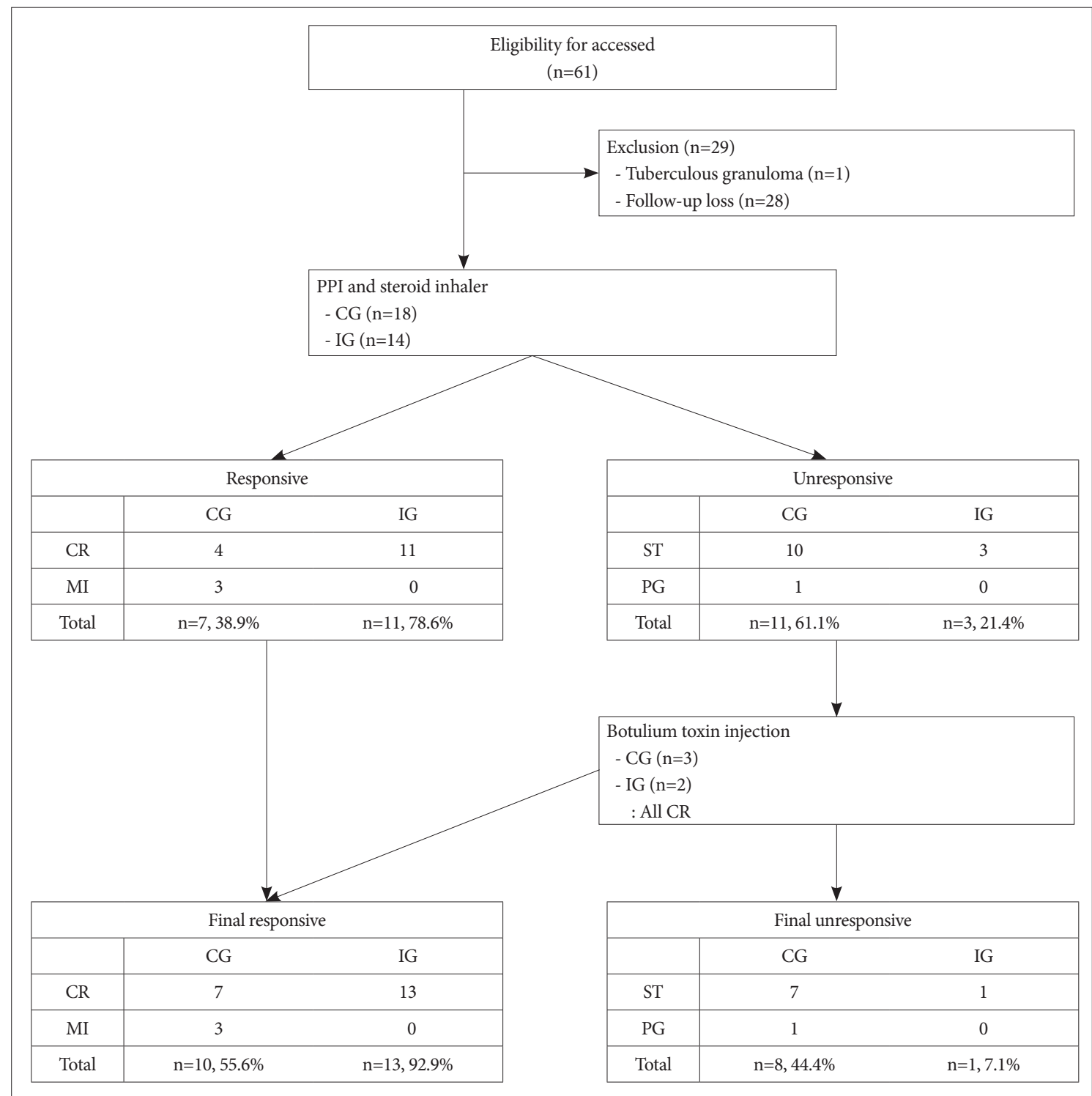

Fig. 3. Participants flow diagram with treatment result. PPI, proton pump inhibitor; CG, contact granuloma; IG, intubation granuloma; CR, complete remission; MI, marked improvement; ST, stationary; PG, progression. 
14 명의 환자 중 5 명의 환자(삽관성 육아종 환자 2 명, 접촉성 육아종 환자 3 명)는 보툴리눔 독소 치료 시행 후 완전히 완치 되었다. 기존 연구에 의하면 성대 육아종에 대한 치료로 보툴 리눔 독소치료가 음성치료, 수술적 절제, 양성자펌프억제제 및 스테로이드 흡입제와 같은 다른 치료 방법에 비해 우수한 효과를 보인다고 보고 되어왔다[9,18,19]. 그러나 보툴리눔 독 소 치료 이후 쉰 목소리나, 연하곤란의 위험이 있으며, 이러한 합병증에 대한 진행된 연구가 없기 때문에 언어 변화 또는 연 하곤란의 정도와 기간을 예측하기가 어렵다. 이러한 합병증 은 환자의 사회적 활동에 심각한 문제를 유발할 수 있으며, 특히 전문적인 음성사용인에게 보툴리눔 독소치료를 기피하 는 주요 요인이 될 수 있다. 본 연구에서는 치료 시작 전 모든 환자들에게 보툴리눔 주사의 효과와 발생 가능한 합병증에 대해 설명하였으며, 그 결과 약물에 반응하지 않은 환자 14 명 (삽관성 육아종 환자 3 명, 접촉성 육아종 환자 11명) 중 5 명만 이 보툴리눔 독소 치료에 동의하였다. 보툴리눔 독소치료를 거부한 9 명의 환자 중 4 명은 전문적인 음성사용인이기 때문 에 목소리가 악화될 위험을 감수할 수 없었고, 5 명은 육아종 에 의한 큰 불편함이 없어 보툴리눔 독소치료를 거부했다. 따 라서, 보툴리눔 독소치료는 접촉성 육아종의 치료제로 가장 효 과적인 치료법일 수 있으나, 발생할 수 있는 합병증과 증상을 고려하여 선택적으로 사용해야 할 것으로 판단된다.

본 연구는 후향적 연구이며 약물 투여기간이나 추적관찰 기간이 너무 짧다는 제한점이 있다. 또한 삽관성 육아종과 접 촉성 육아종 그룹간의 치료 예후에 영향을 미칠 수 있는 기 저 음성습관, 발성 시 기본 주파수 등의 요인에 대한 분석이 진행되지 못하였다. 추후 이를 보완하기 위한 전향적인 연구 의 시행이 필요할 것으로 보인다.

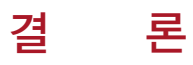

이번 연구는 성대돌기 육아종의 임상적 양상을 분석한 것 으로 삽관성 육아종은 여성에 호발하는 반면 접촉성 육아종 은 남성에 호발하는 것으로 나타났다. 양성자펌프억제제와 스 테로이드 흡입제를 이용한 약물치료에 대한 반응은 삽관성 육아종이 접촉성 육아종에 비해 우수한 것으로 나타났다. 약 물치료에 반응하지 않는 경우 성대 내 보툴리눔 독소 주사가 도움이 될 수 있으며 치료 효과와 합병증 등을 고려하여 선택 적으로 사용할 수 있다.

중심 단어: 성대; 후두; 육아종; 양성자펌프억제제; 보툴리 눔 독소.
Acknowledgments

None

Conflicts of Interest

The authors have no financial conflicts of interest.

Authors' Contribution

Conceptualization: Joo Hyun Woo. Data curation: Jin Uk Jeong, Jae Hwan Oh, Seul Kim, Joo Hyun Woo. Formal analysis: Jin Uk Jeong, Jae Hwan Oh, Seul Kim, Joo Hyun Woo. Funding acquisition: Joo Hyun Woo. Investigation: Joo Hyun Woo, Jae Hwan Oh. Methodology: Joo Hyun Woo, Jae Hwan Oh. Project administration: Jae Hwan Oh. Resources: Joo Hyun Woo. Software: Jin Uk Jeong, Jae Hwan Oh, Joo Hyun Woo. Supervision: Joo Hyun Woo, Dong Young Kim. Validation: Joo Hyun Woo. Visualization: Joo Hyun Woo, Jae Hwan Oh, Jin Uk Jeong. Writing_original draft: all authors. Writingreview \& editing: all authors. Approval of final manuscript: all authors.

\section{REFERENCES}

1. Hong-Gang D, He-Juan J, Chun-Quan Z, Guo-Kang F. Surgery and proton pump inhibitors for treatment of vocal process granulomas. Eur Arch Otorhinolaryngol 2013;270(11):2921-6.

2. Wang CT, Lai MS, Lo WC, Liao LJ, Cheng PW. Intralesional steroid injection: An alternative treatment option for vocal process granuloma in ten patients. Clin Otolaryngol 2013;38(1):77-81.

3. Karkos PD, George M, Van Der Veen J, Atkinson H, Dwivedi RC, Kim D, et al. Vocal process granulomas: A systematic review of treatment. Ann Otol Rhinol Laryngol 2014;213(5):314-20.

4. Ylitalo R, Ramel S. Extraesophageal reflux in patients with contact granuloma: A prospective controlled study. Ann Otol Rhinol Laryngol 2002;111(5 Pt 1):441-6.

5. Leonard R, Kendall K. Effects of voice therapy on vocal process granuloma: A phonoscopic approach. Am J Otolaryngol 2005;26(2):101-7.

6. Martins RH, Branco A, Tavares EL, Iyomasa RM, Carvalho LR, Henry MA. Laryngeal and voice disorders in patients with gastroesophageal symptoms. Correlation with pH-monitoring. Acta Cir Bras 2012; 27(11):821-8.

7. Hillel AT, Lin LM, Samlan R, Starmer H, Leahy K, Flint PW. Inhaled triamcinolone with proton pump inhibitor for treatment of vocal process granulomas: A series of 67 granulomas. Ann Otol Rhinol Laryngol 2010;119(5):325-30.

8. Rimoli CF, Martins RHG, Catâneo DC, Imamura R, Catâneo AJM. Treatment of post-intubation laryngeal granulomas: Systematic review and proportional meta-analysis. Braz J Otorhinolaryngol 2018; 84(6):781-9.

9. Lee SW, Hong HJ, Choi SH, Sun DI, Park YH, Lee BJ, et al. Comparison of treatment modalities for contact granuloma: A nationwide multicenter study. Laryngoscope 2014;124(5):1187-91.

10. McFerran DJ, Abdullah V, Gallimore AP, Pringle MB, Croft CB. Vocal process granulomata. J Laryngol Otol 1994;108(3):216-20.

11. Lee DH, Yoon TM, Lee JK, Lim SC. Surgical treatment outcomes of vocal process granuloma after endotracheal intubation. J Craniofac Surg 2018;29(4):e387-9.

12. Havas TE, Priestley J, Lowinger DS. A management strategy for vocal process granulomas. Laryngoscope 1999;109(2 Pt 1):301-6.

13. Wani MK, Woodson GE. Laryngeal contact granuloma. Laryngoscope 1999;109(10):1589-93.

14. Roh HJ, Goh EK, Chon KM, Wang SG. Topical inhalant steroid (budesonide, Pulmicort nasal) therapy in intubation granuloma. J Laryngol Otol 1999;113(5):427-32.

15. Wang CP, Ko JY, Wang YH, Hu YL, Hsiao TY. Vocal process granuloma - A result of long-term observation in 53 patients. Oral Oncol 
2009;45(9):821-5.

16. Nasri S, Sercarz JA, McAlpin T, Berke GS. Treatment of vocal fold granuloma using botulinum toxin type A. Laryngoscope 1995;105(6): 585-8.

17. Damrose EJ, Damrose JF. Botulinum toxin as adjunctive therapy in refractory laryngeal granuloma. J Laryngol Otol 2008;122(8):824-8.
18. Yılmaz T, Kayahan B, Günaydın RÖ, Kuşçu O, Sözen T. Botulinum toxin A for treatment of contact granuloma. J Voice 2016;30(6):741-3.

19. Yilmaz T, Süslü N, Atay G, Özer S, Günaydin RÖ, Bajin MD. Recurrent contact granuloma: Experience with excision and botulinum toxin injection. JAMA Otolaryngol Head Neck Surg 2013;139(6): 579-83. 